Universidad de Lima

Facultad de Comunicación

Carrera de Comunicación

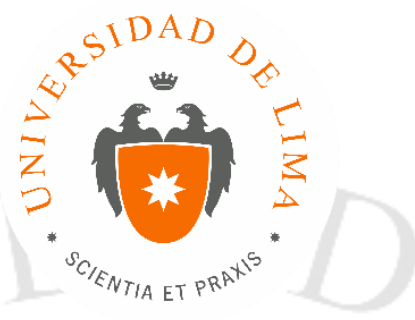

\title{
CONVIRTIENDO LAS QUEJAS EXPUESTAS EN FACEBOOK EN OPORTUNIDADES: EL CASO DE EASY TAXI PERÚ
}

Trabajo de Investigación para optar por la licenciatura en Comunicación

Andrea del Carmen Malavé Neyra 20111420

Asesor

Daniel Cárdenas

Lima - Perú

Setiembre de 2016 


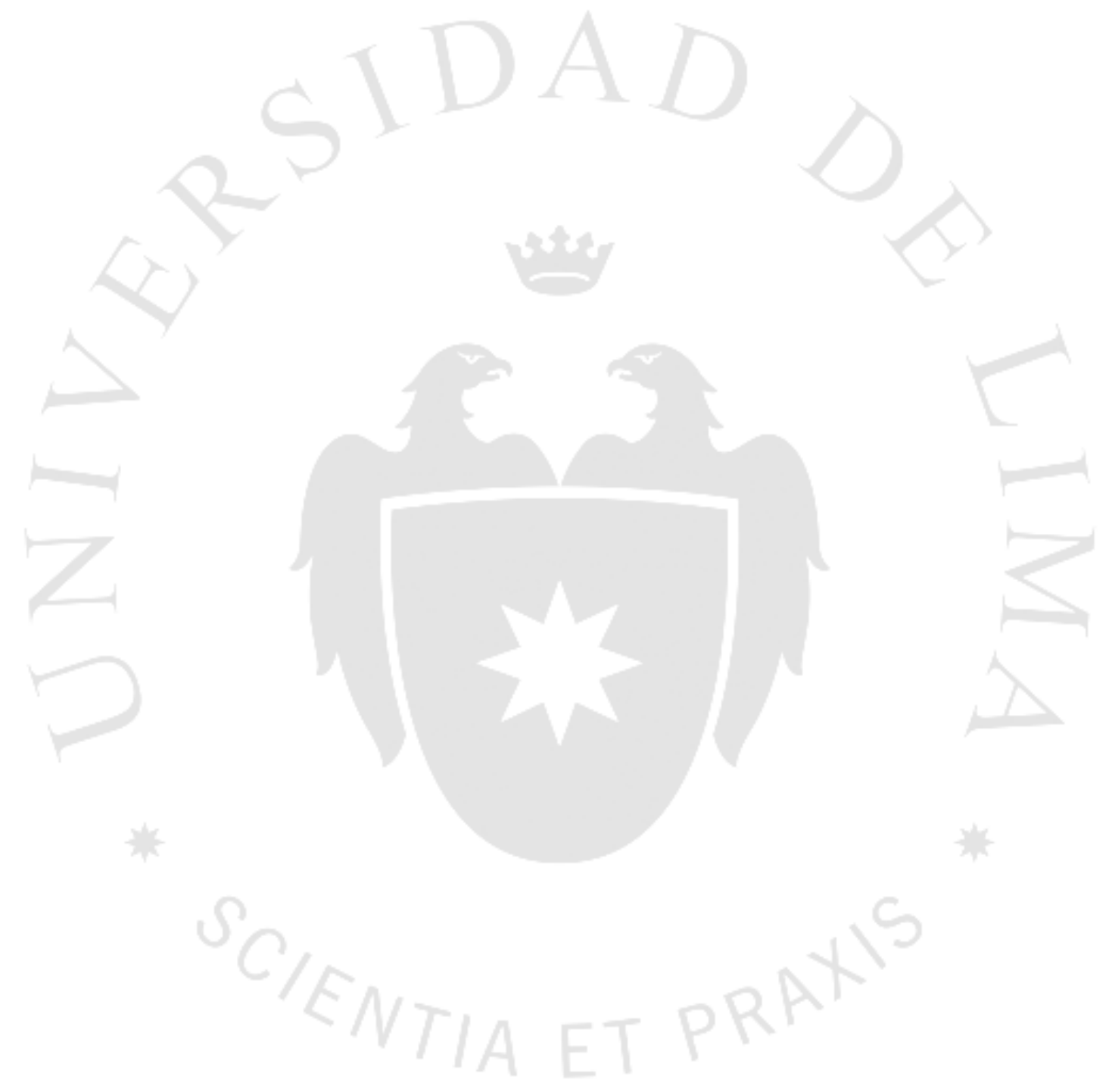


CONVIRTIENDO LAS QUEJAS EXPUESTAS EN FACEBOOK EN OPORTUNIDADES: EL CASO DE EASY TAXI PERÚ 


\section{Resumen}

El presente estudio plantea el paradigma en el que la orientación de la marca es en su totalidad el consumidor, sus emociones y deseos. Enfocándonos en el caso particular de la empresa de servicio Easy Taxi se demuestra, por medio del análisis de los comentarios negativos publicados en su página de Facebook, la apropiación de los mismos como oportunidades de mejora para la empresa. De esta manera se habla de la revalorización de la opinión del consumidor como un factor principal e influyente para cambios del servicio, la toma de decisiones y de estrategias de marketing. Esta apropiación se determina al definir los procesos internos de Easy Taxi, a través de entrevistas a los encargados de las áreas involucradas, la observación de la información expuesta en el fan page de la marca y la percepción del usuario por medio de encuestas. Así, se encuentra la relación entre los datos recogidos que afirma la importancia que hoy en día se le otorga a la queja dentro de las empresas por su exposición en los nuevos canales de comunicación.

\section{Palabras clave}

Quejas, mejora de servicios, oportunidades de marketing, aplicación de taxi. 


\section{TABLA DE CONTENIDOS}

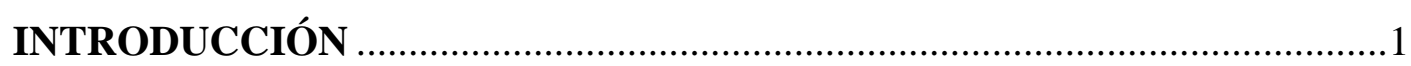

CAPÍTULO I: CONVIRTIENDO QUEJAS EN OPORTUNIDADES ..............

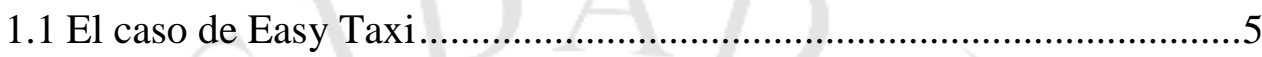

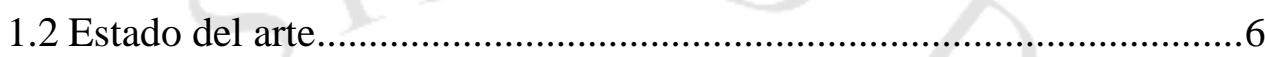

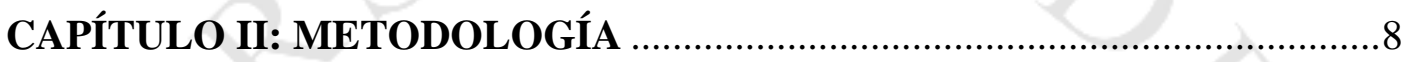

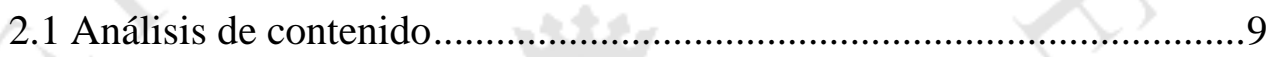

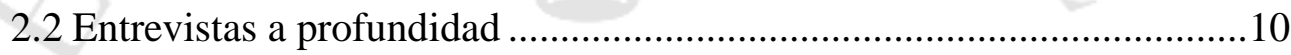

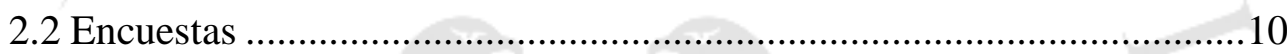

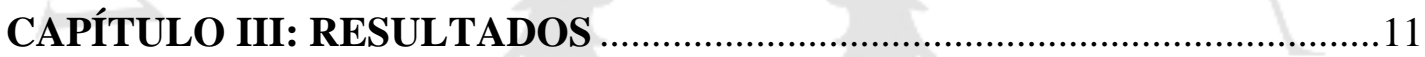

3.1 Los comentarios negativos de Easy Taxi...........................................12

32 Facebook como canal de atención al cliente........................................14

3.3 ¿Easy Taxi elimina los comentarios negativos? ..................................16

3.4 Respuestas y procedimientos frente a quejas y reclamos ......................17

3.4.1 Área de atención al usuario....................................20

3.4.2 Procedimientos..............................................21

3.5 Convirtiendo quejas en oportunidades.............................21

3.4.1 Estrategias de marketing de Easy Taxi... .....................20

3.4.2 Modificaciones de acuerdo al mercado... ......................21

3.4.1 Casos específicos de quejas convertidas en oportunidades........20

3.5 Proceso de apropiación de quejas para realizar mejoras..............21

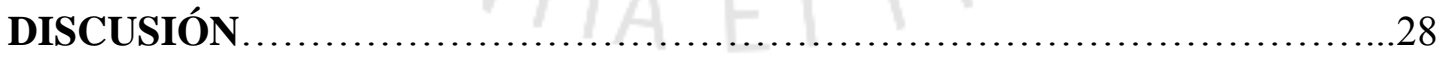

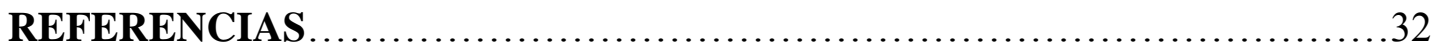




\section{ÍNDICE DE TABLAS}

Tabla 1: Cantidad y tipología de quejas .12

Tabla 2: Cantidad y tipología de respuestas ..........................................................17

Tabla 3: Acciones de comunicaciones y estrategias .................................................22

\section{ÍNDICE DE FIGURAS}

Figura 1: Porcentajes de personas con problemas con la aplicación .........................13

Figura 2: Porcentajes de tipo de problemas con la aplicación ....................................13

Figura 3: Porcentajes de uso de medios de reclamos.............................................15

Figura 4: Porcentajes de la motivación para publicar en Facebook ..........................15

Figura 5: Porcentajes de tipo respuestas de Easy Taxi ............................................18

Figura 6: Porcentajes de respuestas esperadas por los usuarios ...............................19 


\section{INTRODUCCIÓN}

Con la aparición del Internet, no solo el marketing ha evolucionado de una manera significativa, también el concepto del consumidor se ha reconfigurado. Hoy, las marcas interactúan directamente con sus clientes a través de las redes sociales y estos se expresan libremente sobre el producto. Una de las formas de manifestaciones del consumidor hacia la marca corresponde a las quejas que, en la era del social media y el surgimiento de las redes sociales, quedan plasmadas al alcance de todos los clientes.

Por esta razón, la opinión del consumidor se transforma en una exigencia dentro de la empresa, obteniendo un papel importante en la mejora de los productos y servicios; además de ser partícipes activos en la construcción de la marca. Principalmente, en las nuevas compañías que viven en plataformas virtuales, las redes sociales se convierten en herramientas de doble función, tanto de comunicación como de investigación. De esta manera, las empresas aprovechan para extraer insights de los comentarios publicados por usuarios, pudiendo así analizar de manera fácil, directa y económica a su consumidor.

Las investigaciones previas y teorías desarrolladas sobre la repercusión de los comentarios negativos dentro de las empresas se centran en su mayoría en la reputación offline y online de las marcas, crisis de redes sociales y en temas vinculados directamente a la gestión adecuada de las quejas y satisfacción del cliente; sin embargo, son escasas aquellas que profundizan en el manejo interno de los reclamos recibidos, más allá de la resolución puntual del problema, considerando los mismos como información útil e importante para el desarrollo de nuevas estrategias o mejoras enfocadas en deficiencias que el cliente expresa directa y honestamente. 
Por ello, el presente proyecto tiene como finalidad demostrar, mediante el caso específico de la empresa de servicio Easy Taxi, la apropiación de los comentarios negativos expuestos por los usuarios en las redes sociales como oportunidades que revalorizan la opinión del cliente, constituyendo un factor principal e influyente en mejoras del servicio, toma de decisiones, desarrollo de producto y estrategias de marketing, reafirmando la orientación actual de las marcas hacia el consumidor.

En este sentido, se describirán las estrategias de marketing de Easy Taxi enfocadas en los comentarios negativos de los clientes, se identificarán cambios en los servicios de la aplicación como resultado de los comentarios negativos de los consumidores en redes sociales y finalmente se definirán las funciones del área de atención al cliente y el tratamiento de los reclamos. Con ello se busca alcanzar el objetivo general propuesto, enfocado a describir la manera en la que Easy Taxi identifica oportunidades en los comentarios negativos publicados en sus respectivas redes sociales y los incorporan en la elaboración de estrategias de marketing, desarrollo de producto, mejora de servicio y toma de decisiones. 


\section{CAPÍTULO I \\ CONVIRTIENDO QUEJAS EN OPORTUNIDADES}

Como punto de partida, hablaremos de la importancia que se le otorga al cliente en el mundo de las redes sociales. El hecho de que el consumidor tenga la libertad de realizar comentarios de manera pública, directa y global sugiere una reformulación en las estrategias de marketing antes planteadas. Así lo avala Raquel Crespo (2012) al exponer que el objetivo de las marcas, con la aparición de las redes sociales, debería ser el de generar contenido que fomente la participación de los usuarios en donde manifiesten sus experiencias con el producto y así extraer información valiosa para la marca. De ese modo, estaremos hablando de un consumidor que con la aparición de las redes sociales es poseedor de un gran control sobre lo que lee, mira y escribe del producto, esperando ser escuchado (Larry Weber, 2010).

José Luis Sancho (2013) en su artículo "Cliente Non-Stop" se refiere a un consumidor que tiene a su alcance plataformas que le permiten comparar lo que promete una marca con lo que realmente ofrece y así fomentar su opinión, que de manera indirecta, virtual y social lo hará partícipe del proceso de producción, asegurando que el diseño del producto o servicio satisfaga sus deseos.

Así pues, nos enfocaremos en una de las manifestaciones de los consumidores en las redes sociales: las quejas. La mayoría de los consumidores enojados con una empresa se dirigen a los canales de social media desesperados y como última opción para que se les dé una respuesta o solución a sus demandas o inquietudes, pues estos consumidores han entendido la importancia de la repercusión de los comentarios en las redes sociales y la personificación que transmiten las marcas a través de estas (Cristina García, Rocío Nuñez, Nuroa Salas y Olga Suanya, 2013). 
En ese sentido, se busca entender cómo las compañías aprovechan este feedback negativo para desarrollar sus estrategias. Las empresas siempre han estado expuestas a las quejas, incluso antes del desarrollo tecnológico y el contexto actual del social media, y estas expresiones jamás han tenido un significado positivo para las marcas. La reacción ante las quejas suele ser defensiva y con derivación automática al área de atención del cliente y solucionar puntualmente el problema (Janelle Barlon, 2014).

Con la aparición de las redes sociales y la exposición de los comentarios negativos, que han ocasionado un buen número de casos de crisis de reputación online, la mayoría de las marcas han teorizado pasos que se deben seguir para evitar o para frenar estas crisis que afectan directamente a la reputación de las marcas. Sin embargo, Janelle Barlon y Claus Mollar (1999), ya hacían hincapié en que la atención debe ir mucho más allá que el dar respuestas a los clientes insatisfechos. Los reclamos pueden ser de gran ayuda si se saben administrar y aprovechar sin eliminar. Las marcas deben entender que las quejas se convierten en oportunidades que las ayudan a cambiar rápida y económicamente sus productos, el estilo de su servicio o el enfoque del mercado.

Un concepto vinculado con las acciones de las empresas derivadas de estas manifestaciones del consumidor es el CRM (Customer Relationship Management): gestión de relaciones con los clientes. Este término se ha adaptado a la funcionalidad de las redes sociales convirtiéndose en Social CRM, descrito como un enfoque de las estrategias y relación con los clientes, lo cual implica escucharlos constantemente y encontrar oportunidades para mejorar las ventas. Para ello se pretende ir más allá de la respuesta social $\mathrm{y}$ poder extraer conocimiento para poder generar estrategias personalizadas que fidelicen al cliente (David Villaseca Morales, 2014).

Así pues, estaremos frente a las estrategias que propone el libro Marketing 3.0, mismo concepto descrito por Philip Kotler (2012), en donde menciona que la interacción con el consumidor ya no es lo primordial, sino el tomar en cuenta lo que piensa y lo que requiere el mismo para de esta manera ofrecer productos basados en sus emociones. Esta reconceptualización se da por el desarrollo tecnológico y las ventajas que ofrece tanto al consumidor como a la marca. 


\subsection{El caso de Easy Taxi}

En la investigación a presentar nos centraremos en el caso de una empresa de servicio de geolocalización que conecta a usuarios conductores y usuarios pasajeros, desarrollado en un modelo de negocio de aplicativos móviles. Easy Taxi es una startup fundada en el 2011 en Brasil, comprada posteriormente por la empresa alemana Rocket Internet e instalada en el Perú en el 2012 ("Versus de apps". Mercadonegro.pe. 2015/08/06. 25 de septiembre de 2015. http://mercadonegro.pe/noticia/5710/versus-deapps-de-taxi).

Actualmente Easy Taxi tiene como principal competencia a UBER y a Taxi Beat, empresas que se encuentran en etapa de introducción y cuyas estrategias están enfocadas en la captación de nuevos usuarios y no precisamente en la fidelización como es el caso de la empresa a estudiar.

El tipo de servicio que ofrecen estas aplicaciones siempre ha estado sujeto a reclamos, desconfianza y problemas que generalmente no se expresaban públicamente por la inexistencia de un medio que atendiera a estas necesidades. Estas aplicaciones han generado una incipiente formalización del servicio de taxi en el país y de alguna manera han ofrecido los medios por los cuales el cliente puede expresarse, quejarse, agradecer o recibir información y promociones.

Easy Taxi se desarrolla y vive en una plataforma en la que la mayoría de sus clientes corresponden al nuevo consumidor. Por esta razón constantemente se ve expuesta a comentarios, reclamos, sugerencias y preguntas que quedan plasmadas en sus redes. La aplicación ha sido víctima de una serie de denuncias y quejas que se han viralizado hasta llegar a los diarios del país. En una de las entradas del blog cafetaipa.com, titulada "El Caso Easy Taxi: 6 lecciones para empresas y clientes", Santiago Obando describe estas denuncias y la reacción de esta empresa, siendo la misma sumamente cuestionable por ser más defensiva que comprensiva.

Así pues, el propósito de la investigación fue el de describir y definir de qué manera la empresa Easy Taxi, dentro del manejo interno, identifica oportunidades en los comentarios negativos publicados en su página de Facebook y los incorporan en la 
elaboración de estrategias de marketing, desarrollo de producto, mejora de servicio y toma de decisiones.

\subsection{Estado del arte}

Existen investigaciones previas en las que se define el papel del "consumidor 2.0" y su participación a través de los nuevos medios de comunicación, acción que hoy en día resulta fundamental dentro de la empresa, obligando a las mismas a tomar en cuenta las expresiones de los clientes, manejarlas y apropiarlas como materia para el desarrollo de producto y de la marca.

Así pues, con relación a las características del nuevo consumidor Miranda, Rubio, Chamorro y Correira (2015), señalan en su investigación que el proceso de decisión de compra de este se ve directamente afectado y relacionado con la información que él mismo recoge de las redes sociales, la cual es a su vez plasmada por otros usuarios del producto o servicio. De esta manera también concluyen Valerio, Herrera y Martínez (2015), explicando que los comentarios que realizan los clientes del producto o servicio tienen más credibilidad que los contenidos propios de la marca.

Las redes sociales suponen un nuevo medio interactivo de fácil uso, accesible y público en donde las empresas están presentes permitiendo el diálogo con sus clientes. Por tanto, las mismas se presentan como un nuevo espacio en el que las personas, sin someterse a un proceso burocrático, pueden exponer su descontento al momento que quieran, como quieran y desde donde sea. Gracias a la proliferación de herramientas digitales, los clientes pueden plasmar su queja de diferentes formas, como gráfica y audiovisual, y además en diferentes intensidades (Tripp y Gregorie, 2012).

El tema a desarrollar está centrado específicamente en las quejas de los consumidores. Así, Tripp y Gregorie (2012), afirman en un estudio que la mayoría de los clientes que se disponen a exponer sus reclamos en redes sociales se han visto frustrados por intentos de resolución de sus problemas mediante los métodos tradicionales: en la empresa, con los empleados y por líneas de atención al cliente. 
García, Núñez, Salas y Suanya (2012) explican también que al no conseguir solución a sus inquietudes, estos clientes se dirigen a los canales de social media, pues entienden la importancia de la repercusión de sus comentarios y saben que al estar expuestos ante el resto de clientes serán finalmente escuchados por la empresa en cuestión.

Diversos estudios han concluido que las personas que recurren a las páginas de Facebook de compañías de servicios lo hacen principalmente para reportar incidentes y problemas, formular quejas y solucionar dudas. Específicamente un $67 \%$ de consumidores, según estadísticas extraídas de J. D. Power, acuden a estas plataformas en busca de atención al cliente. Estas estadísticas, además, señalan que son las quejas sobre las marcas una de las principales inspiraciones de los usuarios de Internet.

Gardó, Velázquez y Molina (2015) en su investigación hacen énfasis en que las acciones que se toman al resolver problemas están vinculadas con la retención del cliente más que la captación del mismo. Si se ofrece una resolución y dinámica satisfactoria es probable que el usuario continúe con el servicio o de lo contrario cambiará de compañía sin pensarlo. La satisfacción del consumidor después de un fallo en el servicio es mayor que la satisfacción anterior al fallo.

Sin embargo, estudios recientes revelan que las estrategias que aplican las marcas son todavía inefectivas debido a los altos índices de insatisfacción que existen con la solución de quejas y la ausencia de procesos adecuados de tratamiento de quejas (Gardó, Velázquez y Molina, 2015).

De esta manera, enfocándonos en el problema de investigación propuesto, mencionamos a Rabassa y Setó (1998), los cuales desarrollan un artículo que se centra en las quejas del consumidor como instrumento para el marketing relacional. Con ello afirman que una buena gestión de reclamaciones y quejas puede convertirse en una herramienta de gran valor que fomenta las interacciones con el cliente. Asimismo, mencionan que las empresas deben ser capaces de aprovechar al máximo la información que proporcionan las quejas, pues de esta manera se intenta mejorar la calidad de sus productos, servicios e imagen. 


\section{CAPÍTULO II METODOLOGÍA}

Para responder a la pregunta de investigación planteada se emplearon las herramientas que responden al método cualitativo de recolección y combinación de evidencias con el fin de describir, verificar o generar teorías (Martínez, 2016). En ese sentido se utilizó la técnica del análisis de contenido en función a los comentarios negativos y publicaciones en el fan page de Easy Taxi. A su vez, se realizaron encuestas a usuarios de la aplicación para tener un acercamiento a la percepción de los mismos, consiguiendo así la generalización de una opinión. Finalmente se entrevistaron a los encargados de las áreas involucradas dentro de la empresa para determinar los procedimientos internos relacionados a las quejas y reclamos.

La naturaleza del trabajo fue de tipo descriptiva e ilustrativa, pues los procesos y acciones tanto de la empresa de servicio Easy Taxi, como de los usuarios de las mismas, fueron observados e interpretados con el fin de comparar o coincidir con la teoría desarrollada previamente y las investigaciones halladas, para así poner en manifiesto las prácticas de gestión de la empresa ante el problema de investigación (Yin, 1994) citado en (Martínez, 2006). Se buscó identificar y describir los factores que se asocian al fenómeno explorado y a través de estos se relacionó y contrastó la teoría con la realidad observada del objeto de estudio (Martínez, 2006).

Es importante destacar que la elección del caso específico de Easy Taxi, como objeto de estudio, fue dado por factores vinculados a la naturaleza del servicio que fueron óptimos para demostrar la hipótesis de apropiación de comentarios negativos y su conversión en oportunidades para la empresa. Este tipo es llamado caso "teórico" y se escoge para probar algún aspecto de una teoría (Muñiz, 2010). 


\subsection{Análisis de contenido}

Nuestra primera unidad de análisis corresponde a los usuarios del fan page de Easy Taxi. Se observaron los comentarios negativos publicados por los clientes en el fan page, siguiendo una matriz de elaboración propia la cual clasifica y sugiere una tipología de quejas para su análisis posterior. Uno de los objetivos de investigación se refiere a la relación existente entre los comentarios negativos y las mejoras del servicio. Para identificar este vínculo se establecieron tres indicadores a seguir para el análisis de las quejas y reclamos: frecuencia de quejas, tipología de quejas y respuestas de la página.

La muestra de comentarios negativos se seleccionó por el período de tiempo entre los meses de febrero del 2015 a abril del 2016. De este período únicamente se seleccionaron los comentarios de publicaciones que no estuvieran referidas a nuevas promociones o concursos. Así pues, se obtuvieron aquellos reclamos o quejas únicamente relacionados a aspectos genéricos y constantes percibidos del servicio. Se ha abarcado la mayoría de los comentarios de las publicaciones del 2015, pues para efectos de contrastar las mejoras y estrategias actuales de la marca, las quejas debían ser realizadas con un espacio de tiempo previo considerable para la posible reacción de la aplicación.

En el período seleccionado la cantidad de comentarios en las publicaciones, omitiendo las promociones y concursos, fue 4512. De este número se pudieron determinar 100 quejas o reclamos que cumplían con las pertinencias para posibles cambios y mejores en el servicio de la aplicación. Este número se manejó como muestra seleccionada.

Posteriormente se analizaron las estrategias y acciones tomadas por la empresa que se ven plasmadas en su fan page. Se identificaron y describieron al detalle las publicaciones que contenían las comunicaciones más relevantes promoviendo campañas, nuevas funcionalidades, cambios en el servicio o comunicados importantes. Para esto nos guiamos por indicadores que ayudaron a organizar y clasificar la 
información: mejoras y novedades del servicio, campañas (estrategias de marketing) y comunicados informativos.

La muestra fue seleccionada del período de Enero a Mayo de 2016. Las publicaciones se tomaron de este período de tiempo para encontrar la relación entre las quejas y reclamos publicados en el año anterior. Así, se buscó definir si las estrategias publicadas en el período escogido fueron respuesta a estos comentarios negativos.

\subsection{Entrevistas a profundidad}

Se realizaron las entrevistas a profundidad a los encargados de las áreas de Marketing y el área de Consumer Care de Easy Taxi. Las mismas fueron orientadas a alcanzar los objetivos vinculados en describir las estrategias de marketing enfocadas en los comentarios negativos de los clientes y en identificar cambios en los servicios de Easy Taxi como resultado de los reclamos y quejas de los consumidores. Asimismo, se buscó determinar el proceso de atención al cliente y casos específicos de apropiación de la queja para la conversión de las mismas en mejoras de la empresa.

Los indicadores que guiaron la entrevista de Sergio Moreno, marketing manager, fueron el manejo de las quejas, la importancia de las quejas dentro del área, las estrategias orientadas al usuario y las quejas convertidas en oportunidades. En cuanto a los indicadores establecidos para la entrevista con Gianfranco Díaz, consumer care manager, estuvieron la definición del área de Atención al Usuario, los procedimientos y manejos de quejas, las denuncias y quejas convertidas en oportunidades.

\subsection{Encuestas:}

Se realizaron encuestas para tener una aproximación a la percepción de un grupo de usuarios de Easy Taxi con respecto a sus motivaciones al publicar las quejas 
en el fan page de la marca, así como su punto de vista del manejo de las quejas y reclamos por parte de la empresa. Esta herramienta se utilizó para la recolección de datos que reflejaron una idea sobre el aspecto a investigar.

La muestra que se escogió fue de 60 usuarios de la aplicación, incluyendo a los que han tenido algún tipo de problema y a los que no. Estos usuarios corresponden al grupo objetivo de clientes de la aplicación, siendo este de hombres y mujeres entre los 18 a los 54 años (S. Moreno, comunicación personal, 15 de junio del 2016). Asimismo, para seleccionar a los encuestados se utilizó el muestreo intencional en el que los elementos de la población son elegidos bajo criterio y juicio del investigador, teniendo en cuenta que las características de los sujetos a encuestar correspondan a lo requerido para alcanzar los objetivos planteados (Namakforoosh, 2000).

Las preguntas de las encuestas se centraron en responder a uno de los objetivos específicos de la investigación que se relaciona con explorar el comportamiento de los usuarios de la aplicación tras realizar una queja o reclamos y lo que esperan de la misma como procedimientos o soluciones de los problemas que se presentan.

\section{CAPÍTULO III RESULTADOS}

\subsection{Los comentarios negativos de Easy Taxi}

A partir del análisis del fan page de Easy Taxi se pudieron extraer las quejas y reclamos realizados por los usuarios, estableciendo una tipología que las agrupa y que a su vez define la frecuencia de exposición. Así pues, tenemos, en primer lugar, que la mayoría de los comentarios negativos publicados en Facebook se refieren a las quejas 
relacionadas con las tarifas que maneja la empresa, siendo los usuarios reiterativos en los precios variables, problemas para la visualización de la tarifa y precios no acordes al tarifario. En segundo lugar tenemos las denuncias hacia los choferes, encontrando distintos motivos que promueven la queja hacia estos.

\section{Tabla 1: Cantidad y tipología de quejas}

Cantidad y tipología de quejas publicadas por los usuarios de Easy Taxi en el fan page de la aplicación.

\begin{tabular}{|c|c|c|}
\hline Tipo de queja & Quejas de usuarios & Cantidad \\
\hline Tarifas & $\begin{array}{l}\text { - Precios variables por cuadrante. } \\
\text { - Problemas con el tarifario. } \\
\text { - Precios no acorde al tarifario. } \\
\text { - Cobro indebido del chofer. }\end{array}$ & 27 \\
\hline $\begin{array}{l}\text { Denuncias hacia los } \\
\text { choferes }\end{array}$ & $\begin{array}{l}\text { - Negación para realizar el servicio a destinos } \\
\text { alejados. } \\
\text { - Negación del aire acondicionado. } \\
\text { - Calificación al chofer y visualización de la } \\
\text { misma. } \\
\text { - Presentación del chófer y del auto. } \\
\text { - Comportamiento de los choferes. } \\
\text { - Dudas de filtros para elección de choferes. }\end{array}$ & 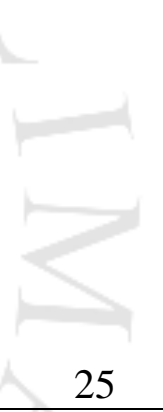 \\
\hline Sistema de pagos & $\begin{array}{l}\text { - Problemas con el pago de tarjetas crédito y } \\
\text { débito. }\end{array}$ & 6 \\
\hline Atención al cliente & $\begin{array}{l}\text { - No resolución de problema. } \\
\text { - Insistencia en problemas no atendidos. }\end{array}$ & 3 \\
\hline $\begin{array}{l}\text { Denuncia por parte de los } \\
\text { choferes }\end{array}$ & $\begin{array}{l}\text { - Comportamiento del cliente. } \\
\text { - Molestia por las denuncias hacia su } \\
\text { persona. } \\
\text { - Precios bajos. }\end{array}$ & 19 \\
\hline Casos particulares & $\begin{array}{l}\text { - Desconocimiento procedimiento de } \\
\text { promociones. } \\
\text { - No disponibilidad de taxis. } \\
\text { - Fallo de registro en aplicación. } \\
\end{array}$ & 20 \\
\hline
\end{tabular}

De acuerdo a los resultados que arrojaron las encuestas realizadas a los usuarios pasajeros, se determinó que del $100 \%$ de encuestados más de la mitad ha tenido algún tipo de problema con la empresa. De estos usuarios, el $29.7 \%$ coincide con 
la tendencia del motivo de las quejas, en relación a las tarifas, que se pudo observar en el fan page.

\section{Figura 1: Porcentajes de personas con problemas con la aplicación}

Porcentaje de distribución de respuestas a la pregunta: ¿Has tenido algún tipo de problema con Easy Taxi?, de la encuesta realizada los usuarios de Easy Taxi.

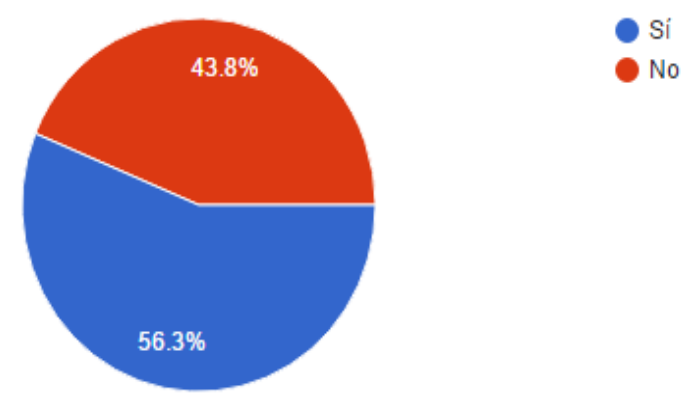

\section{Figura 2: Porcentajes de tipo de problema con la aplicación}

Porcentaje de distribución de respuestas a la pregunta: ¿Qué tipo de problema has tenido?, de la encuesta realizada los usuarios de Easy Taxi.

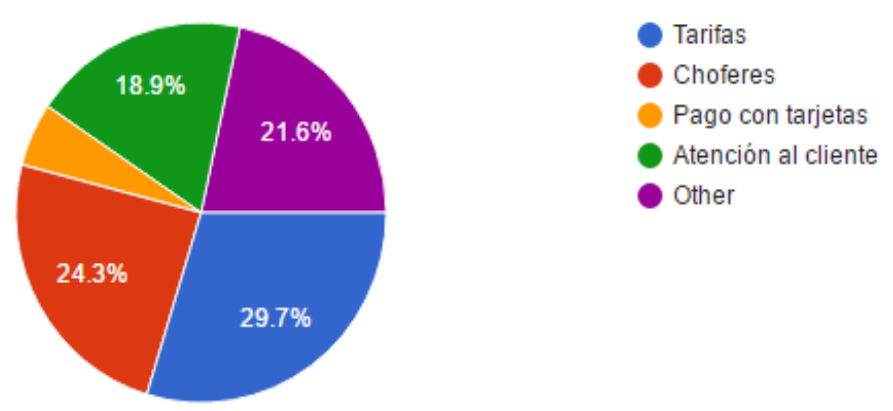

Luego de realizado el análisis externo, con información proveniente del fan page de la marca y de los usuarios de la aplicación, se determinaron las quejas que tienen un grado de relevancia significativo al interno. Tras efectuar las entrevistas a los encargados del área se pudieron definir tipologías que afirman lo observado, “[...] para 
organizar todas las quejas que ingresan por nuestros canales de atención, nosotros tipificamos” (G. Díaz, comunicación personal, 1 de julio del 2016).

Así pues, el área de Consumer Care, con el fin de ordenar, derivar y resolver de una manera efectiva y eficiente los casos, clasifican las quejas y sugerencias de acuerdo a su tipo: tarifas, robos, pérdidas y hallazgos, corporativos, accidentes, problemas de recarga, problemas con facturas y denuncias. Esta tipificación se realiza a grandes rasgos, pues a su vez dentro de cada tipo hay subcategorías. Para las quejas sobre tarifas se definen las siguientes categorías: no ingresó bien el destino, conductor cobra de más, bugs de la aplicación, entre otros.

En cuanto a las quejas que afectan considerablemente a la marca, se afirma que estas son aquellas con un contenido de alto potencial para la viralización, más que ciertos tipos de comentarios con una frecuencia de exposición constante. "Definitivamente las quejas que más nos afectan como marca son las que denuncian o difaman a un conductor y viralizan el caso en redes sociales" (S. Moreno, comunicación personal, 15 de junio del 2016). Así también afirma lo que observamos en el fan page:

Desde que ingresó Easy Taxi como una buena propuesta, nueva y diferente a lo que tenía el mercado existió el problema de que al final del viaje no se sabía cuánto cobrar. El 90\% de las quejas que teníamos en un inicio eran de tarifas. No hay taxímetro pues no tenemos leyes de transporte para taxistas en cuanto a cobro, no está regulado" (S. Moreno, íd., 2016).

\subsection{Facebook como canal de atención al cliente}

El área de Marketing de la empresa es la encargada de la recepción de quejas provenientes del fan page. Todo parte del reporte del community manager, quien es el que notifica el caso y hace el traslado al área de Consumer Care en donde se realiza el proceso posterior al reclamo (S. Moreno, íd., 2016).

Si bien Easy Taxi cuenta con diferentes canales de atención al cliente (redes sociales, call center, correo electrónico y la aplicación), según las encuestas realizadas a los 
usuarios de la aplicación, Facebook se encuentra en segundo lugar como medio para realizar algún tipo de reclamo. De las 36 personas que afirman haberse quejado, 9 de estas lo han hecho a través de Facebook y 11 por el correo de atención al usuario.

\section{Figura 3: Porcentajes de medios de reclamo}

Porcentaje de distribución de respuestas a la pregunta: ¿A través de qué medio te has quejado?, de la encuesta realizada los usuarios de Easy Taxi.

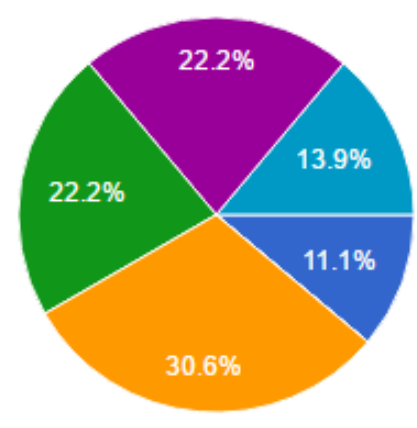

Facebook (Fan Page)

Twitter

Correo de Easy Taxi Atención al Cliente

Teléfono de Easy Taxi Atención al

Cliente

Por medio del App

Facebook (Fan page)

Para el área de Marketing de Easy Taxi las redes sociales tienen mayor importancia por la exposición de los comentarios que afecta la reputación. "Es común que los usuarios expongan sus quejas en redes sociales, pues hay más exposición y tienen posibilidad de ser atendido más rápido" (S. Moreno, íd., 2016). Esto se complementa con lo encontrado en las encuestas a los usuarios, en donde de las 56 personas que respondieron a la pregunta “¿Por qué publicarías tu queja en Facebook?”, 26 personas coincidieron en hacerlo para advertirle a los demás usuarios acerca del problema.

\section{Figura 4: Porcentajes de motivación para publicar en Facebook}

Porcentaje de distribución de respuestas a la pregunta: ¿Por qué publicarías tu queja en Facebook?, de la encuesta realizada los usuarios de Easy Taxi. 


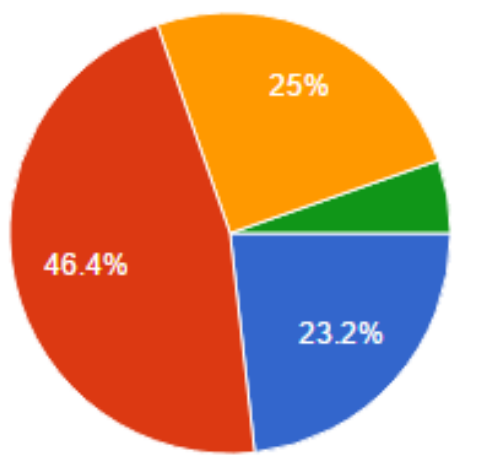

No atienden por los medios tradicionales

Quiero advertir a los demás usuarios al exponer mi queja

Es el medio más accesible para quejarme

No me atendieron por los medios tradicionales

Por otro lado, el área de Consumer Care se encarga de recibir los comentarios negativos de todos los canales y aseguran que "las quejas publicadas en Facebook y en Twitter son un reflejo de los reclamos que se manejan por medio de los otros canales de atención” (G. Díaz, íd., 2016). Así también, Gianfranco Díaz argumentó en la entrevista:

La prioridad de resolución de casos se le otorga generalmente a los usuarios que han publicado su queja al público y muestran una actitud de alteración, así el caso no sea tan grave como algún otro que se haya comunicado por un canal privado.

\section{3 ¿Easy Taxi elimina los comentarios negativos?}

De acuerdo a lo observado en el fan page y lo recolectado en las entrevistas se determinó también que una gran cantidad de comentarios son eliminados de la página. En el período de un año las quejas más relevantes fueron únicamente las 100 que se analizaron para la presente investigación y según el consumer care manager únicamente por medio del fan page la marca recibe un número aproximado de treinta quejas diarias. De todos los reclamos se elimina una cantidad significativa, pues las publicaciones no cumplen con los términos y condiciones de la página. 
Los comentarios se dejan ahí, salvo que rompa los términos y condiciones de nuestro fan page. Por ejemplo, si estás publicando una foto de uno de nuestros conductores y estás diciendo algo negativo con los datos que proporciona la aplicación, tenemos que borrarlo por la Ley de Protección de Datos, y cuando hay comentarios con lenguaje inapropiado también se borra. Pero sí tratamos de dejar la mayoría. Nosotros igual tratamos de ser lo más transparentes posibles (S. Moreno, íd., 2016).

Finalmente, con respecto a la eliminación de los comentarios, Gianfranco Díaz comentó que cuando la queja está en redes, puede llegar a desatar una crisis. Si bien el reclamo podría borrarse, la capacidad de respuesta por el lado de Easy Taxi es mucho más rápida lo que evita el malestar del afectado al no ver su comentario en la página.

\subsection{Respuestas y procedimientos frente a quejas y reclamos}

De acuerdo al análisis realizado en el fan page, se determinaron patrones de respuestas que nos permitieron agrupar las mismas en diferentes tipos. De esta manera se pudo observar la ausencia de respuesta a los comentarios negativos que publican los usuarios, de 100 quejas extraídas, más de la mitad (52 quejas) no obtuvieron respuesta alguna.

\section{Tabla 2: Cantidad y tipología de las respuestas}

Cantidad y tipología de las respuestas de Easy Taxi a las quejas publicadas en el Fan Page.

\begin{tabular}{|c|c|c|}
\hline Tipo de respuesta & Respuestas de Easy Taxi & $\begin{array}{l}\text { Canti } \\
\text { dad }\end{array}$ \\
\hline No hubo respuesta & - No hubo respuesta. & 52 \\
\hline $\begin{array}{l}\text { Se tomará en cuenta la } \\
\text { sugerencia }\end{array}$ & $\begin{array}{l}\text { - Agradecemos tu sugerencia, se la comentaremos al } \\
\text { área encargada. } \\
\text { - Estamos trabajando para mejorar la experiencia de } \\
\text { nuestros usuarios. } \\
\text { - Gracias por la sugerencia. La comentaré al área }\end{array}$ & 14 \\
\hline
\end{tabular}




\begin{tabular}{|c|c|c|}
\hline & $\begin{array}{l}\text { encargada. } \\
\text { - Lamentamos inconvenientes y valoramos tus } \\
\text { sugerencias. }\end{array}$ & \\
\hline $\begin{array}{l}\text { Esta queja ha sido } \\
\text { atendida }\end{array}$ & $\begin{array}{l}\text { - Gracias por escribirnos. Se está atendiendo el caso } \\
\text { con la debida reserva. } \\
\text { - Ya lo atendimos. }\end{array}$ & 4 \\
\hline $\begin{array}{l}\text { Respuesta de otros } \\
\text { usuarios }\end{array}$ & & 1 \\
\hline Contacto por privado & $\begin{array}{l}\text { - Contáctanos vía inbox. } \\
\text { - Comunícate al correo o al teléfono. }\end{array}$ & 20 \\
\hline Respuesta explícita & $\begin{array}{l}\text { - Explicación del uso del filtro del aire. } \\
\text { - Explicación del filtro del aeropuerto. } \\
\text { - Visualización del tarifario. } \\
\text { - Explicación de la calificación al finalizar el viaje. } \\
\text { - Explicación del sistema de pago. } \\
\text { - Explicación de selección de personal. }\end{array}$ & 9 \\
\hline
\end{tabular}

Así también los usuarios que fueron encuestados confirmaron lo observado en el fan page, pues la mayoría expresó que no haber recibido respuesta por parte de la empresa al realizar su queja por cualquier canal de atención. Otro grupo reducido de encuestados marcó la opción en la que se indicaba que las respuestas obtenidas fueron predeterminadas y automáticas.

\section{Figura 5: Porcentaje de respuestas de Easy Taxi}

Porcentaje de distribución de respuestas a la pregunta: ¿cuál fue la respuesta brindada por la empresa?, de la encuesta realizada los usuarios de Easy Taxi.

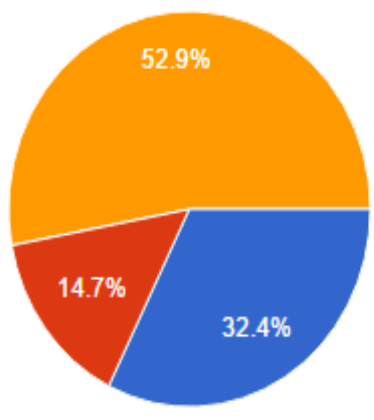

Respuesta automática

Respuesta personalizada

No hubo respuesta 
Con respecto a las respuestas automáticas señaladas en las encuestas y a los patrones encontrados, definimos mediante las entrevistas que Easy Taxi maneja macros de respuestas destinadas a cada tipo de caso. Se busca personalizar, pero el sentido de las mismas responden al patrón ya predeterminado. "Estos macros se cambian cada tres o cuatro meses pues el usuario peruano es exigente y puede notar cuando las respuestas ya están programadas y genera malestar, así el caso les sea resuelto" (G. Díaz, íd., 2016).

De las encuestas realizadas también es importante resaltar, en relación al manejo de las quejas, que los usuarios esperan en su mayoría (56.5\%) la resolución inmediata del problema, más que disculpas o recompensas. Asimismo, con respecto al tema planteado, el $21 \%$ de los encuestados espera mejoras en la aplicación después de quejarse. Sin embargo, es posible, que estos usuarios busquen las mejoras a largo plazo, mientras que a corto plazo esperan que la empresa resuelva puntualmente su caso.

\section{Figura 6: Porcentajes de respuestas esperadas}

Porcentaje de distribución de respuestas a la pregunta: ¿cómo esperas que la empresa responda a la queja?, de la encuesta realizada los usuarios de Easy Taxi.

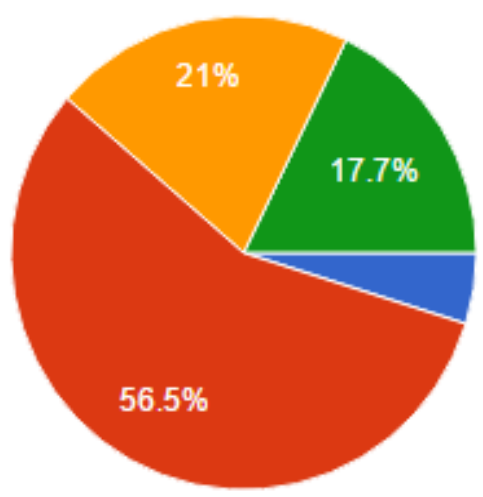

Disculpas

Solución del problema

Mejoras en el servicio y aplicación

Recompensa 


\subsection{1 Área de Atención al Usuario}

Tras las entrevistas, se determinaron procesos y acciones que se llevan a cabo al interno. La definición del área de Atención al Usuario la indicó Gianfranco Díaz, como el área que condensa toda la información recibida, encargada de realizar la investigación profunda de los casos, de implementar sistemas de gestión, de tipificar y de entender el porqué de las quejas después de que las mismas sean debidamente atendidas. Es un área que se ha ido formando y sigue evolucionando por ensayo y error. Las acciones tomadas y las respuestas de los usuarios frente a ellas han permitido que el área se fortalezca en cuanto a gestión de quejas. "Con el tiempo nos hemos dado cuenta que esto es una de las cosas más importantes que debemos de tener y tenemos que cuidar” (S. Moreno, íd., 2016).

Gianfranco Díaz menciona que por el crecimiento de la empresa y el funcionamiento de la misma a nivel global, surge la necesidad de crear el área de Atención al Usuario. Esta área absorbe e integra el call center que tiene como función específica recibir, gestionar y derivar cualquier tema que se presente al momento, al igual que el community manager quien deriva los reclamos que recibe en el fan page.

Frente a la competencia, Easy Taxi se diferencia por la capacidad que ha desarrollado para resolver los casos presentados por los usuarios.

Otras aplicaciones no tienen una infraestructura tan grande como la nuestra. Ellos hacen buenos filtros, pero al final lo que ves es qué tanto da la cara la empresa frente a situaciones que puedan pasar, y en Perú somos nosotros quienes tenemos esta infraestructura capaz e inmediata (S. Moreno, íd., 2016).

Los objetivos del área de Atención al Usuario, van más allá de la resolución del caso y lograr la satisfacción del mismo. En Easy Taxi los objetivos de esta área están estrechamente relacionados con los objetivos generales de la empresa: "Mejora de la aplicación, mejorar los bugs y la satisfacción del usuario” (G. Díaz, íd., 2016). 


\subsubsection{Procedimientos}

En rasgos generales, Gianfranco explica que el área se maneja con un software de atención al cliente llamado Zendesk, el cual integra todos los canales de atención de la empresa: redes sociales, call center, correo electrónico y aplicación, haciendo más fácil y rápida la gestión. Además, proporciona eficazmente gráficos, estadísticas e informes avanzados con datos relevantes para las demás áreas de la empresa.

Sin embargo, dentro de este proceso de gestión existen acciones más específicas, en especial, para tratar casos vinculados a denuncias a usuarios conductores, que según lo analizado corresponden a una de las quejas más frecuentes. Esto se realiza con el $90 \%$ de los reclamos que se reciben, pues el $10 \%$ restante corresponden a casos que pueden resolverse por medio de los canales de atención de una manera más rápida.

Lo primero que se realiza al recibir una queja clasificada como relevante, por el grado de la denuncia, es contactar al usuario conductor, bloquearle la cuenta preventivamente, citarlo a la oficina para que realice su descargo y lo mismo por el lado del usuario pasajero. Una vez evaluado el caso, con la información y pruebas se procede a tomar las acciones necesarias (S. Moreno, íd., 2016).

La mayoría de estas fuertes denuncias son falsas. Los malentendidos y los incidentes siempre terminan perjudicando a los conductores, incluso Gianfranco Díaz dice: "[...] también hay quejas sembradas de la competencia para dañar nuestra imagen de marca a través de la reputación online". Sin embargo, la empresa es cuidadosa en cuanto a la viralización y no se escatima el seguimiento de ningún caso.

\subsection{Convirtiendo las quejas en oportunidades}

El análisis de contenido del fan page nos permitió conocer y extraer cuáles han sido las mejoras y campañas que la marca ha comunicado al usuario, en el periodo de 
tiempo establecido en la metodología, y que de cierto modo se vinculan con las quejas y reclamos mencionados anteriormente.

\section{Tabla 3: Acciones de comunicación y estrategias}

Acciones de comunicación y estrategias realizadas por Easy Taxi y publicadas en su Fan Page.

\begin{tabular}{|c|c|c|c|}
\hline Acción & Nombre & Descripción & Publicación \\
\hline $\begin{array}{l}\text { Nueva } \\
\text { funcionalidad }\end{array}$ & $\begin{array}{l}\text { Easy } \\
\text { Connect }\end{array}$ & $\begin{array}{l}\text { Función que } \\
\text { permite } \\
\text { localizar a los } \\
\text { taxistas que } \\
\text { estén } \\
\text { registrados y se } \\
\text { encuentran } \\
\text { cerca del } \\
\text { usuario. }\end{array}$ & $\begin{array}{l}\text { Presentamos Easy Taxi Connect, la } \\
\text { nueva funcionalidad de la aplicación } \\
\text { que te permite verificar qué usuarios } \\
\text { conductores están registrados en la } \\
\text { comunidad Easy Taxi y así empezar tu } \\
\text { viaje más rápido que nunca. } \\
\text { En el siguiente video te explicamos } \\
\text { cómo utilizarlo. }\end{array}$ \\
\hline $\begin{array}{l}\text { Nueva } \\
\text { funcionalidad }\end{array}$ & $\begin{array}{l}\text { Califica tu } \\
\text { viaje }\end{array}$ & $\begin{array}{l}\text { Función que } \\
\text { permite } \\
\text { calificar con } \\
\text { estrellas el } \\
\text { viaje. }\end{array}$ & $\begin{array}{l}\text { Califica tu viaje y ayúdanos a mejorar } \\
\text { para darte una experiencia de } 5 \text { estrellas } \\
\text { siempre. }\end{array}$ \\
\hline $\begin{array}{l}\text { Comunicació } \\
\text { n informativa }\end{array}$ & $\begin{array}{l}\text { ¿Cómo usar } \\
\text { código } \\
\text { promocional } \\
?\end{array}$ & $\begin{array}{l}\text { Video } \\
\text { explicativo } \\
\text { sobre cómo } \\
\text { usar los } \\
\text { descuentos con } \\
\text { los códigos } \\
\text { promocionales. }\end{array}$ & $\begin{array}{l}\text { ¿Tienes un código promocional pero no } \\
\text { sabes cómo usarlo? } \\
\text { Solo sigue estos simples pasos para } \\
\text { validar tu descuento antes de solicitar un } \\
\text { viaje por medio de la aplicación. :) } \\
\text { ¿Qué esperas? }\end{array}$ \\
\hline $\begin{array}{l}\text { Comunicació } \\
\text { n informativa }\end{array}$ & $\begin{array}{l}\text { Proceso de } \\
\text { registro } \\
\text { usuarios } \\
\text { conductores }\end{array}$ & $\begin{array}{l}\text { Comunicación } \\
\text { sobre la serie } \\
\text { de pasos que } \\
\text { debe pasar un } \\
\text { conductor para } \\
\text { ser parte de } \\
\text { Easy Taxi. }\end{array}$ & $\begin{array}{l}\text { El pasado miércoles } 30 \text { de marzo, en } \\
\text { esta red social, una pasajera dio a } \\
\text { conocer su malestar respecto a una } \\
\text { conversación con un usuario conductor, } \\
\text { ante este hecho queremos comunicarles } \\
\text { a todos ustedes lo siguiente: (se } \\
\text { enumeran las acciones a tomar de Easy } \\
\text { Taxi). }\end{array}$ \\
\hline $\begin{array}{l}\text { Nueva } \\
\text { funcionalidad }\end{array}$ & $\begin{array}{l}\text { Pago con } \\
\text { Visa }\end{array}$ & $\begin{array}{l}\text { Función que } \\
\text { permite pagar } \\
\text { con tarjeta de } \\
\text { crédito y } \\
\text { débito. }\end{array}$ & \\
\hline
\end{tabular}




\begin{tabular}{|c|c|c|c|}
\hline $\begin{array}{l}\text { Mejora en la } \\
\text { aplicación }\end{array}$ & $\begin{array}{l}\text { Nueva } \\
\text { experiencia } \\
\text { Easy taxi }\end{array}$ & $\begin{array}{l}\text { En enero de } \\
2016 \text { lanzan la } \\
\text { actualización de } \\
\text { la aplicación. }\end{array}$ & $\begin{array}{l}\text { Mejor interfaz, código de promoción, } \\
\text { ingreso de destino antes del viaje, } \\
\text { conductor acepta viaje. }\end{array}$ \\
\hline $\begin{array}{l}\text { Comunicació } \\
\mathrm{n} \text { informativa } \\
\text { - Nueva } \\
\text { funcionalidad }\end{array}$ & Tarifario & $\begin{array}{l}\text { Se comunica } \\
\text { por medio de } \\
\text { post y } \\
\text { respuestas } \\
\text { programadas } \\
\text { con imagen de } \\
\text { cómo usar el } \\
\text { tarifario. }\end{array}$ & $\begin{array}{l}\text { ¿Necesitas saber cuánto te saldría tu } \\
\text { viaje? } \\
\text { No te preocupes, con Easy Taxi puedes } \\
\text { ver el tarifario referencial en todo } \\
\text { momento sin la necesidad de realizar un } \\
\text { viaje. Sólo ingresa las zonas a las cuales } \\
\text { pertenecen las direcciones de inicio y } \\
\text { destino y listo. } \\
\text { \#EasyTips. }\end{array}$ \\
\hline
\end{tabular}

Entre las publicaciones se distinguen: nuevas funcionalidades de la aplicación, mejoras y comunicados informativos que respondan a los deseos del consumidor expresado en los comentarios que dejan en el fan page.

Así podemos relacionar, desde una perspectiva netamente externa, las estrategias con los reclamos más significativos como es el caso de las quejas por las tarifas, siendo el nuevo tarifario una mejora que se desprende de esta queja. Lo mismo se puede observar con respecto de los comentarios negativos sobre los usuarios conductores, cuando la marca comunica los procesos de registro de choferes y la nueva funcionalidad de calificación del viaje.

\subsubsection{Estrategias de marketing de Easy Taxi}

De acuerdo a la entrevista realizada a Sergio Moreno, se puede afirmar que la aplicación es líder en el mercado peruano. Los objetivos de la marca en esta etapa son diferentes a los de hace tres años y a los de su actual competencia, la cual se encuentra en una etapa de introducción en la que necesariamente necesita promover campañas dirigidas a nuevos usuarios, regalar viajes y ofrecer descuentos.

El mercado está creciendo y dado que nuestra base ya es lo suficientemente grande, preferimos fidelizar que captar usuarios nuevos. Sabemos que muchos usuarios 
se van a la competencia por diferentes temas y lo que nos toca a nosotros es realizar campaña de reactivación para retenerlos (S. Moreno, íd., 2016).

Es por esto que el servicio en base a insights encontrados en el usuario en redes es importante para orientar las estrategias. Easy taxi ya cuenta con la capacidad de respuesta y equipo de trabajo ante situaciones de denuncia, por lo que actualmente dirigen sus esfuerzos en mantener a sus usuarios. "Estamos posicionándonos como una lovemark" (S. Moreno, íd., 2016).

Para enfocarse en los deseos del consumidor, Easy Taxi utiliza diferentes herramientas para estudiar su mercado: governance, las entrevistas NPS, las encuestas cuantitativas y cualitativas; sin embargo, se destacan las redes sociales con el mismo peso para recoger información de los usuarios: "Las redes sociales te dan el verdadero feeling del consumidor" (S. Moreno, íd., 2016), y eso se interpreta por medio de los comentarios.

\subsubsection{Modificaciones de acuerdo al mercado}

Se han desarrollado una serie de aspectos que no se contemplan en los demás países donde opera la aplicación. Easy Taxi Perú, por la complejidad del mercado, se ha visto forzado a cambiar o incluir aspectos siendo la mayoría de las veces el encargado de dar la pauta al resto de países en cuanto a innovación o mejoras.

Yo he pasado un tiempo en Easy Taxi Argentina, después me trasladaron a México, de ahí a Centro América y luego me han transferido acá. Y no sé qué ha pasado, pero la gente se queja en exceso. Te exigen un montón y a veces son irracionales. (S. Moreno, íd., 2016).

Gianfranco asegura en la entrevista realizada que el funcionamiento de Easy Taxi es el mismo para todos los países en los que se encuentra la empresa. Sin embargo, los algoritmos de la aplicación sí pueden variar, al igual que los procesos internos de la empresa y las campañas o promociones, para así optimizar los resultados. Esto se ve 
influenciado directamente por las necesidades y el comportamiento del mercado donde esté operando la aplicación, no restándole importancia a las sugerencias y reclamos de los usuarios.

En el caso de Easy Taxi Perú, existen una serie de diferencias con los demás países por las peculiaridades del mercado peruano.

Una de las características principales de estos consumidores es la costumbre de un servicio de transporte informal, en donde la inexistencia de un taxi regulado con marcador de tarifa ha influenciado en gran medida en aspectos básicos de la aplicación (G. Díaz, íd., 2016).

\subsubsection{Casos específicos de quejas convertidas en oportunidades}

Luego de la información recolectada proveniente de los encargados de las áreas de Atención al Usuario y de Marketing, se pueden describir las acciones que se han tomado partiendo principalmente de las constantes quejas y reclamos recibidas, junto a otros aspectos que sustentan la toma de decisiones. Así tenemos:

El sistema de calificación: Mejora relacionada con las denuncias hacia los choferes. Permite condensar todo el feedback del usuario y tomar medidas sobre comportamientos indebidos de usuarios taxistas, antes de posibles denuncias publicadas en medios. Ayuda a filtrar conductores. Antes no contaban con este sistema y no había manera de saber la conducta del usuario conductor si el usuario pasajero no lo reportaba por correo. "Hoy en día si tiene menos de 4.7 estrellas no puede seguir en la plataforma, al tener este sistema nos ayuda a identificar más rápido lo de los conductores y a depurarlos que por más que pasen todos sus filtros tienen una actitud inadecuada" (S. Moreno, íd., 2016).

Capacitaciones: Antes consistía en un tiempo de una hora. Actualmente se hacen capacitaciones de tres horas en las que se muestran casos pasados de denuncias y 
aspectos obvios de mal comportamiento, que finalmente podrían escaparse de sus manos si no son mencionados.

Tarifario: Perú es el primer y único país en el que opera la aplicación en contar con un tarifario web y para smartphone. Surge de la volatilidad de precios a los que en un inicio se veían perjudicados clientes usuarios. Se definía por cuadrante establecido al interno, que muchas veces resultaban injustos y cambiantes, terminando en quejas por los usuarios acostumbrados a negociaciones. Ahora los precios son fijos y pueden ser calculados antes de tomar el servicio y evitar así posibles reclamos.

Cobro tarjetas en soles: Reiteradas quejas y sugerencias con respecto al nuevo cobro del servicio a través de tarjeta de crédito o débito, pues el banco facturaba en dólares, lo cual perjudicaba al usuario haciéndose sentir en las redes sociales. Esto promovió que Easy Taxi buscara una alianza con VisaNet para resolver este problema, siendo los primeros y únicos en realizar el cobro con tarjeta en soles satisfaciendo así las necesidades del usuario, "Esto partió $100 \%$ por lo que los usuarios pedían en redes" (S. Moreno, íd., 2016).

Filtros: Sugerencias de usuarios que solicitaban aire acondicionado en la unidad y conductores negados por falta de equipamiento o por variantes y aspectos que le impedían usar el mismo. Estas quejas se reflejaban en los canales de atención y se decidió colocar el filtro de aire acondicionado y así el usuario pueda escoger el taxista con este servicio. Asimismo sucedía con el transporte hacia el aeropuerto, muchos choferes se negaban a aceptar este recorrido causando malestar en el usuario.

La aplicación se actualiza en función de pasajeros y conductores. El filtro del aire ahora se convirtió en un estándar. Esas observaciones pasaron a ser una opción del producto y ahora esa opción se ha vuelto un estándar del producto. (G. Díaz, íd., 2016).

\subsection{Proceso de apropiación de quejas para realizar mejoras}


Basándonos en las entrevistas realizadas a los encargados de las áreas a investigar determinamos que existe un claro vínculo entre el área de Atención al Usuario y el área de Marketing, que a la vez es transversal con otras áreas, como por ejemplo el área de Producto. La información recolectada por las sugerencias y quejas ayuda a entender y reflejan un panorama rápido y de primera mano acerca de lo que el consumidor está esperando de la marca.

Se puede decir que a partir de ciertas quejas el área de Marketing puede planificar campañas o acciones dirigidas específicamente a cubrir necesidades expuestas al público en las redes. Claro está que toda sugerencia que clasifica como una posible mejora del servicio o modificación del producto, es evaluada previamente cruzando información cuantitativa y cualitativa resultado de investigaciones de mercado.

Al final todo lo movemos por números, agarras tus KPIS. Al final decir "yo creo que esto es lo mejor" no sirve. Si ves que necesitas un desarrollo en la aplicación tienes que sustentarlo con indicadores. Pido al CM, "hazme un reporte de todas las sugerencias que han pedido usar tarjeta de crédito en redes" (ejemplo) y en base a [sic] eso tú determinas si ves los porcentajes favorables. Hay que justificar con números y se hace el desarrollo (S. Moreno, íd., 2016).

Para que pueda existir un cambio en la aplicación es necesario que el número de las sugerencias o reclamos sea constante y frecuente; además, estas quejas deben significar un paso más allá que la resolución directa y personalizada del incidente. Cuando estas quejas similares y recurrentes llegan a tres mil mensuales salen del área de Atención al Usuario para ser atendidas o, en su defecto, advertidas por las áreas vinculadas, pues corresponden a una oportunidad de mejora de algún aspecto que falla y genera malestar y reclamos por parte del usuario pasajero o conductor. "El área de Atención al Usuario tiene vínculo directo con todas las áreas, pues alimentamos de información valiosa para mejoras y oportunidades" (G. Díaz, íd., 2016).

Generalmente hay reuniones con los managers y los jefes de áreas en donde se mencionan este tipo de casos y se evalúan para realizar alguna acción. Gianfranco, 
encargado del área de Atención al Usuario alega que los cambios no son directos. Recibir quejas y pasarlas al área correspondiente no significa la mejora inmediata. Es necesario que la casa matriz, ubicada en Brasil, apruebe este tipo de cambios y el proceso parte del consumidor.

Las áreas que establecen un contacto directo con el usuario alimentan a los jefes de información y estos a su vez la trasladan a los city manager que se reúnen semanalmente con las cabezas del resto de países y finalmente llega a la casa matriz para que el caso sea evaluado con el debido sustento (G. Díaz, comunicación personal, 1 de julio de 2016).

\section{DISCUSIÓN}

El objetivo de la presente investigación se enfocó en determinar si, y de qué manera, las empresas apropian los comentarios negativos que los usuarios expresan en el fan page de la marca convirtiéndolos en oportunidades de negocio. Para demostrar este fenómeno el artículo se centró en el caso específico de la empresa de servicios Easy Taxi Perú, describiendo los procesos internos, acciones y percepciones en relación a las quejas o reclamos.

A lo largo del estudio se determinó, a través del análisis interno y externo de la empresa, que Easy Taxi integra y relaciona los procedimientos del área de Atención al Usuario, encargados de gestionar las quejas y reclamos, con las demás áreas de la empresa, logrando así que el feedback significativo y reiterante de los usuarios se conviertan en estrategia.

Las publicaciones en el fan page de Easy Taxi demuestran las acciones más representativas que se han tomado y se han comunicado a los usuarios, siendo la 
mayoría de estas acciones respuestas a las necesidades que expresa constantemente el consumidor de este servicio. Así pues, se afirma con las entrevistas, que la relación encontrada entre las quejas y las estrategias halladas en el fan page corresponden a las mapeadas y ejecutadas por las áreas estudiadas de Easy Taxi, siendo estas resultado neto de los reclamos del usuario.

Es importante recalcar que la facilidad con la que la aplicación recibe los comentarios negativos para generar mejoras constantes se debe a la naturaleza del negocio. Al ser esta una start up, la innovación y el mantenerse al nivel de la competencia son constantes que el usuario, por medio de la comparación, es quien lo expresa en forma de reclamo o sugerencia por los canales de atención.

Podemos decir, entonces, que en el caso específico de Easy Taxi más que considerar estas acciones "cambios estructurados o mejoras de un servicio ya establecido", se trata de una construcción continua de la marca y del servicio donde los usuarios son partícipes activos y claves a través de los comentarios que plasman en el fan page. Las actualizaciones de la aplicación responden a un consumidor que exige un producto moldeado a sus deseos y necesidades. Esto afecta e influye directamente en las emociones del consumidor porque se topa con una marca que lo escucha y lo entiende así como Phillip Kotler menciona en su libro Marketing 3.0: "La interacción con el consumidor ya no es lo primordial, sino el tomar en cuenta lo que piensa y lo que requiere el mismo para de esta manera ofrecer productos basados en sus emociones".

Luego de lo investigado se entiende que Easy Taxi Perú es líder en el mercado y que sus campañas están orientadas a la fidelización de los clientes. Así, entonces, argumentamos que cuando una empresa se encuentra en una etapa de maduración, sus estrategias y objetivos ya no están orientadas a la captación de nuevos usuarios, sino en la retención de sus actuales clientes. Por esta razón el caso escogido describe la apropiación de las quejas, pues es una vía por la cual se obtiene información directa del consumidor, avalando a Gardó, Velázquez y Molina (2015) cuya investigación hace énfasis en que las acciones que se toman al resolver problemas están vinculadas con la retención del cliente más que la captación del mismo y que la satisfacción después de un fallo resuelto es mayor a la satisfacción habitual. 
Podemos ver también cómo son las quejas y los reclamos las expresiones más sinceras del consumidor hacia la marca, pues antes de abandonar el servicio e ir con la competencia espera un cambio o una respuesta que lo motiven a continuar con la aplicación. Además de la resolución puntual del problema, que siempre es esperada en primer lugar, esperan que el inconveniente cese por completo para el público en general.

Esto está relacionado con el uso de Facebook como medio para expresar las quejas, pues como hemos encontrado en la investigación, el usuario decide hacerlo por no haber sido atendido por los demás canales y para advertir a los demás del problema, pues este reconoce que, como mencionan Valerio, Herrera y Martínez (2015), los comentarios que realizan los clientes del producto o servicio tienen más credibilidad que los contenidos propios de la marca.

Así también observamos cómo y por qué Easy Taxi coloca principal atención en los comentarios del fan page, a pesar de no ser estos los más recurrentes. La reputación juega un papel importante en el proceso de manejo de quejas, pues aunque se desvíe del tema principal de investigación, sale a flote al identificar las acciones inmediatas que se toman cuando un comentario, sustancial o no para la mejora de servicio, es publicado en redes sociales y tiene posibilidad de viralizarse.

Es importante mencionar que, incluso para Easy Taxi, que va actualizando sus servicios gracias al feedback del usuario, la necesidad de resolver los temas puntualmente por el tema de la reputación muchas veces deja en segundo plano la resolución a largo plazo de los casos en cuestión.

Sin embargo, la empresa investigada reconoce la importancia que las redes sociales merecen como herramientas que extraen información del cliente, dando a conocer lo que ellos mismos valoran y por qué deciden comprar sus productos o servicios. Ayudan a generar el valor añadido que posicionará a la marca en la mente del mismo consumidor.

Después de realizada la presente investigación se podría definir procedimientos que teoricen la apropiación de las quejas como oportunidades. Si bien el 
estudio estuvo enfocado en un solo caso, lo hallado es generalizable para empresas de la misma naturaleza. Así pues, las quejas y reclamos serían parte de estudios cualitativos necesarios para conocer al consumidor.

Ha quedado demostrado, mediante el caso analizado, que la información cualitativa y cuantitativa extraída de las redes sociales tiene tanta validez como la proveniente de otras herramientas de investigación, siendo conveniente establecer metodologías que evalúen y seleccionen los comentarios que puedan resultar útiles en el proceso de diseño de producto.

Siguiendo el ejemplo de Easy Taxi y apoyándonos en la teoría desarrollada por López-Fresnos (2011) es necesaria la vinculación del gestor de redes sociales con diferentes departamentos que se integren para actuar en función a las quejas recibidas. Entre estas áreas mencionamos a los expertos en atención al cliente, quienes serán los primeros en defender la empresa contra los ataques de los clientes: el de comunicaciones que sabrá los mecanismos para responder de forma adecuada y el de marketing para realizar estrategias de acuerdo a la información obtenida con el fin de satisfacer y retener al consumidor.

Para futuros estudios es recomendable realizar la comparación de dos casos, uno en etapa de introducción y otro en la etapa de maduración. De esta manera se puede detallar el porqué de las diferencias en cuanto al manejo de las quejas y la posible apropiación. Así también se podría trabajar una investigación únicamente desde el punto de vista del consumidor, ubicando una muestra más grande que pueda contrastar y confirmar si efectivamente estos perciben cambios luego de realizado el descargo de su queja. 


\section{REFERENCIAS}

Barlow, J. (2014). El valor de la marca en el servicio al cliente: el nuevo margen competitivo. Barcelona: Gestión 2000, 2005.

Barlow, J., y Moller, C. (1999). Una queja es un favor: cómo utilizar los comentarios de los clientes como herramienta estratégica. Bogotá: Norma, 1999.

Crespo, R. A. (2012). Planificación estratégica en medios digitales: Internet y redes sociales. Planificación estratégica y gestión de la publicidad, 235.

García, C., Núñez, R., Salas, N., y Suanya, O. (2013). El cliente social: Los retos de la atención al cliente en el universo de las redes sociales. Barcelona: Profit, 2013.

Gardó, T. F., Velázquez, B. M., y Molina, M. E. R. (2015). ¿Es posible aumentar la satisfacción del cliente después de una queja?: La paradoja de recuperación del servicio en el comercio minorista. Universia Business Review, (46).

Kotler, P. (2012). Marketing 3.0. Bogotá: Ediciones de la U, 2012.

López-Fresno, P. (2011) Gestión de las reclamaciones: de la insatisfacción a la fidelidad, 241. Editorial AENOR - Asociación Española de Normalización y Certificación.

Martínez Carazo, P. C. (2011). El método de estudio de caso Estrategia metodológica de la investigación científica. Revista científica Pensamiento y Gestión, (20).

Miranda González, F. J., Rubio Lacoba, S., Chamorro Mera, A., y Correia Loureiro, S. M. (2015). Determinantes de la intención de uso de Facebook en el proceso de decision de compra/Determining factors of the intended use of Facebook in the purchase decision process. Investigaciones Europeas de Dirección y Economía de la Empresa (IEDEE), 21(1), 26-34. 
Muñiz, M. (2010). Estudios de caso en la investigación cualitativa. División de Estudios de Posgrado Universidad Autónoma de Nuevo León. Facultad de Psicología. México, 1-8.

Namakforoosh, M. N. (2000). Metodología de la investigación. Editorial Limusa.

Rabassa-Figueras, Noemí, y Setó Pàmies, Dolors. Marketing Relacional: La gestión de las reclamaciones y quejas de los clientes. Ciencias empresariales/ FCA UMSNH 15, No.2 (1998): 15-29.

Ruiz, M., y Palací, F. J. (2012). Nuevas tecnologías y psicología del consumo. El boca a boca y el papel de las redes sociales. Boletín de psicología, (104), 57-72.

Sancho, J. L. (2013). Harvard Deusto: Marketing y ventas. Estrategias de marketing, ventas y atención al cliente para el nuevo modelo de cliente 'non stop'. p. 70-7.

Sarabia Sánchez, José Francisco y Parra Meroño, María Concepción. El comportamiento de queja y reclamación y la insatisfacción del consumidor. Estudios sobre consumo 59 (2001): 9-21.

Tripp, T. M., y Grégoire, Y. (2012). Cuando los clientes descontentos contraatacan en Internet. Harvard Deusto Business Review, (208), 40-51.

UBER: Los taxis y la tecnología se fusionan en el Perú. (2014, 12 de septiembre). Recuperada el 7 de septiembre de 2015 de http://peru.com/epic/epicusers/uber-taxis-y-tecnologia-se-fusionan-peru-noticia-283663.

Valerio, G., Herrera-Murillo, D. J., Villanueva-Puente, F., Herrera-Murillo, N., y Del Carmen Rodríguez-Martínez, M. Relación entre los formatos de publicación y el engagement digital: estudio de las páginas de Facebook de las universidades mexicanas.

Villaseca Morales, D. (2014). Innovación y marketing de servicios en la era digital. Madrid: ESIC, 2014.

Versus de apps. (2015, 08 de junio). Recuperada el 25 de septiembre de 2015 de http://mercadonegro.pe/noticia/5710/versus-de-apps-de-taxi).

Weber, L. (2010). Marketing en las redes sociales (2.a edición). México, D.F.: McGraw-Hill, 2010. 


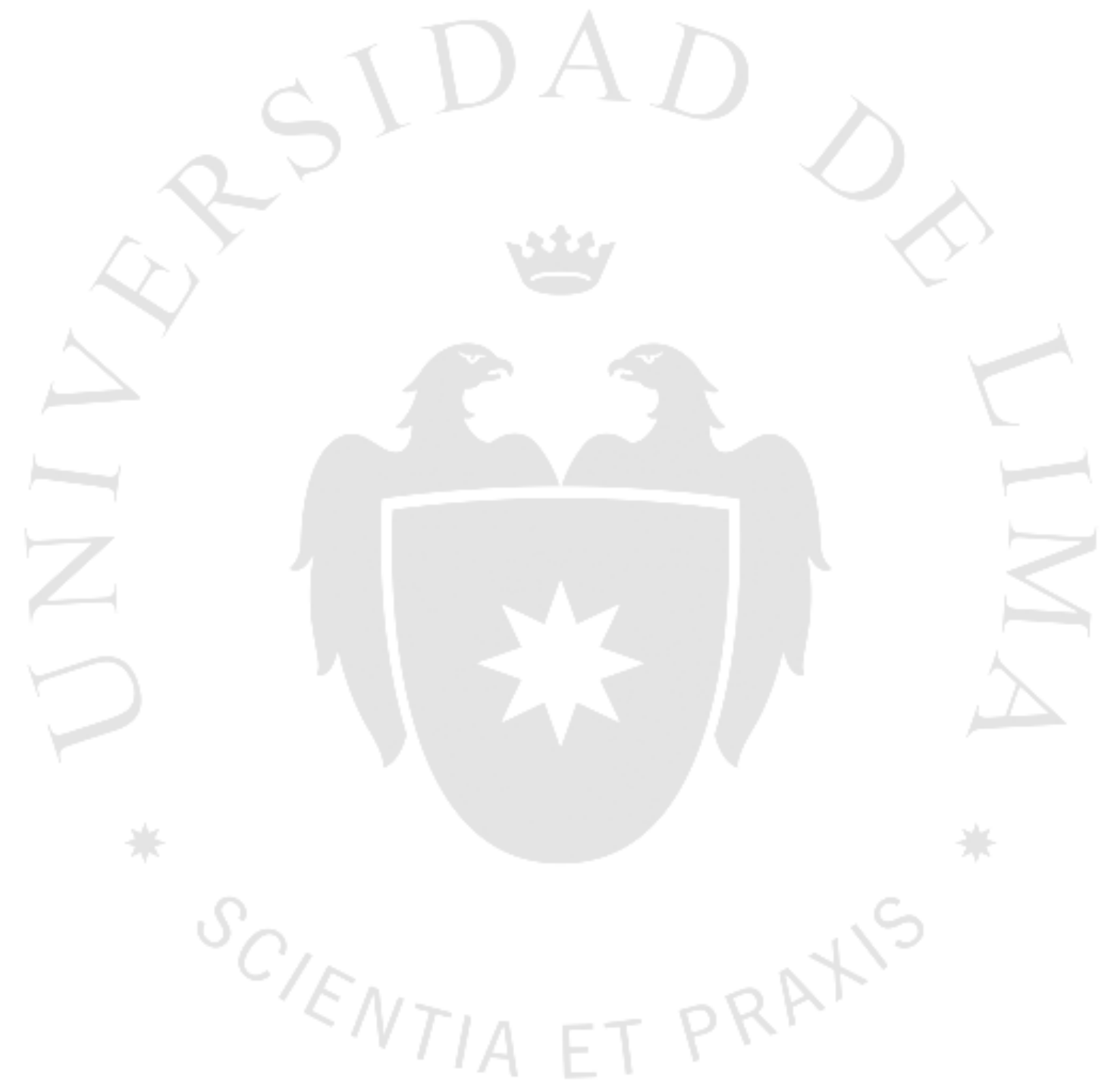

